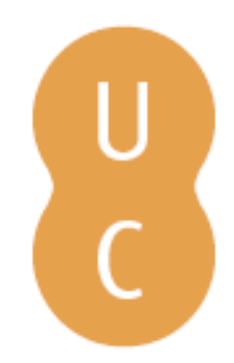

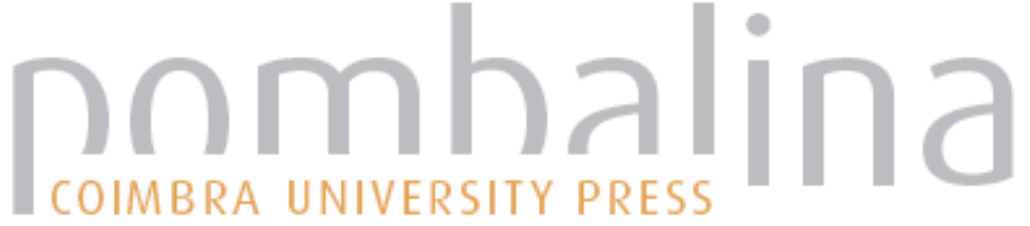

\section{Aplicação de técnica multivariada à razão de mistura do ar em Minas Gerais/Brasil}

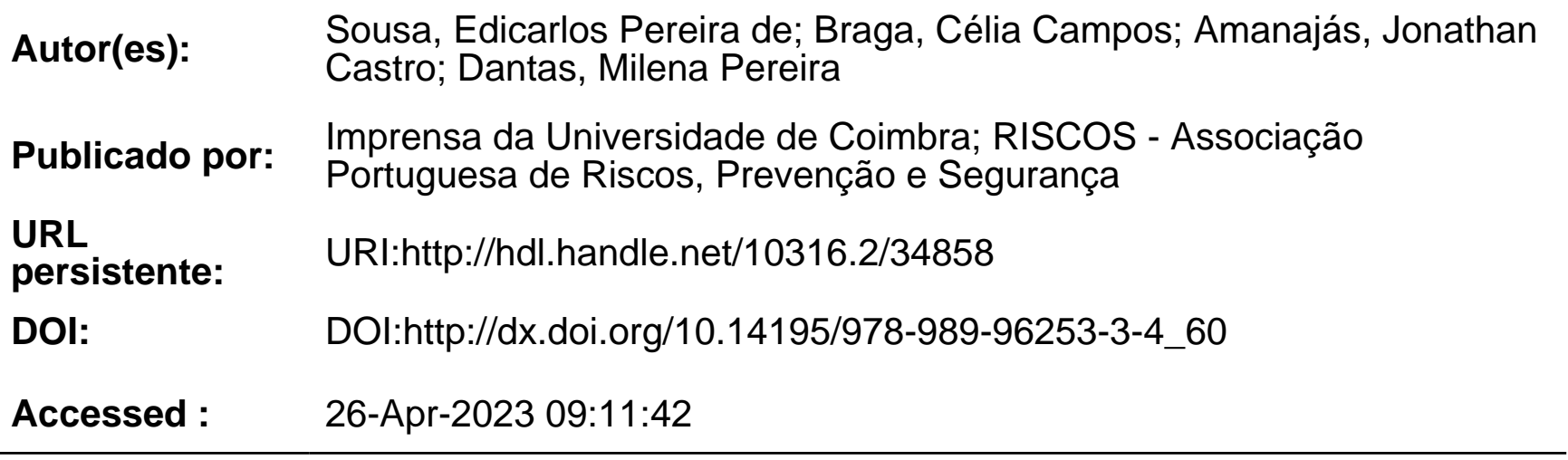

A navegação consulta e descarregamento dos títulos inseridos nas Bibliotecas Digitais UC Digitalis, UC Pombalina e UC Impactum, pressupõem a aceitação plena e sem reservas dos Termos e Condições de Uso destas Bibliotecas Digitais, disponíveis em https://digitalis.uc.pt/pt-pt/termos.

Conforme exposto nos referidos Termos e Condições de Uso, o descarregamento de títulos de acesso restrito requer uma licença válida de autorização devendo o utilizador aceder ao(s) documento(s) a partir de um endereço de IP da instituição detentora da supramencionada licença.

Ao utilizador é apenas permitido o descarregamento para uso pessoal, pelo que o emprego do(s) título(s) descarregado(s) para outro fim, designadamente comercial, carece de autorização do respetivo autor ou editor da obra.

Na medida em que todas as obras da UC Digitalis se encontram protegidas pelo Código do Direito de Autor e Direitos Conexos e demais legislação aplicável, toda a cópia, parcial ou total, deste documento, nos casos em que é legalmente admitida, deverá conter ou fazer-se acompanhar por este aviso.

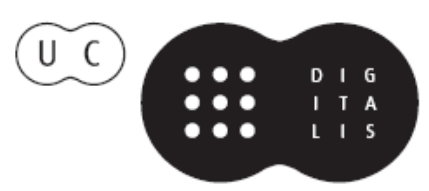



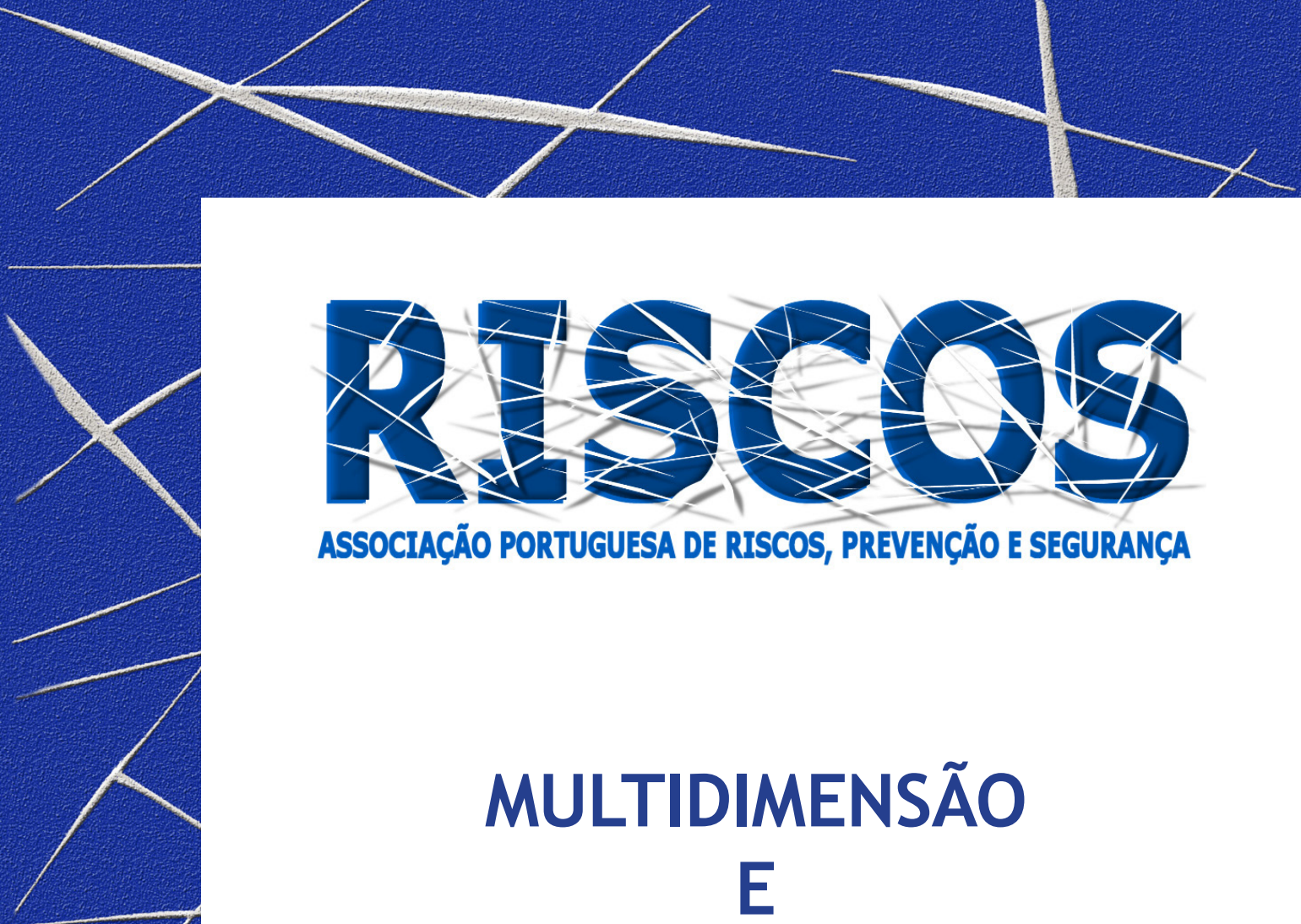

ASSOCIAÇÃO PORTUGUESA DE RISCOS, PREVENCCÃO E SEGURANÇA

MULTIDIMENSÃO

E
TERRITÓRIOS DE RISCO

III Congresso Internacional

I Simpósio Ibero-Americano

VIII Encontro Nacional de Riscos

Guimarães

2014 


\title{
APLICAÇÃO DE TÉCNICA MULTIVARIADA À RAZÃO DE MISTTURA DO AR EM MINAS GERAIS/BRASIL
}

\author{
Edicarlos Pereira de Sousa \\ Universidade Federal de Campina Grande - CTRN/UACA \\ edicarlos.p.sousa@gmail.com
}

Célia Campos Braga

Universidade Federal de Campina Grande - CTRN/UACA celia@dca.ufcg.edu.br

Jonathan Castro Amanajás

Universidade Federal de Campina Grande - CTRN/UACA jonathan.amanajas@hotmail.com

Milena Pereira Dantas

Universidade Federal de Campina Grande - CTRN/UACA milena@dca.ufcg.edu.br

\begin{abstract}
RESUMO
Este trabalho tem por objetivo determinar padrões espaço-temporais da razão de mistura, definida como a quantidade de vapor d'água por unidade de massa do ar seco, e associá-los aos sistemas meteorológicos atuantes no Estado de Minas Gerais. Para isso, empregou-se a técnica de ACP aos dados mensais de razão de mistura de 39 estações climatológicas com 30 anos comuns de observações. 0 emprego da ACP mostrou a existência de dois padrões dominantes da razão de mistura que explicaram aproximadamente $98 \%$ da variância total dos dados. 0 primeiro, relacionado à maior concentração de umidade, mostra a atuação da ZCAS, dos sistemas frontais e influência orográfica. O segundo está associado a ASAS. Neste contexto, os resultados obtidos a partir da ACP evidenciaram que as chuvas de verão e outono são influenciadas pelas ZCAS e pelos sistemas frontais. No inverno, esses sistemas enfraquecem e a intensidade das chuvas diminui na região.
\end{abstract}

Palavras-chave: umidade, ACP, sistemas meteorológicos

\section{Introdução}

O Brasil possui a maior parte de seu território inserido nas latitudes baixas, com extensa costa oceânica, cujo interior está sujeito aos efeitos da continentalidade nos períodos de estiagem. A variabilidade sazonal de algumas variáveis climatológicas na região central do país faz a população passar por longos períodos sem chuva e, nesse caso, são muitos os impactos ocasionados pelo calor e baixa umidade atmosférica.

O vapor d'água tem papel essencial no balanço de energia próximo à superfície e é fundamental no ciclo hidrológico. Sendo um ótimo absorvedor de radiação infravermelha, desempenha papel de agente termorregulador, impedindo que a camada de ar mais próxima ao solo seja resfriada em excesso durante a noite e, além disso, representa a maior fonte de energia latente da atmosfera tropical (Vianello \& Alves, 1991).

A variabilidade climática de Minas Gerais é bem diversificada, seja como resposta de seus aspectos topográficos, sua posição geográfica e, principalmente, os aspectos dinâmicos da atmosfera, que incluem os sistemas meteorológicos de micro, meso e grande escalas, que atuam direta ou indiretamente no regime pluvial, como a Zona de Convergência do Atlântico Sul (ZCAS) e Sistemas Frontais, principais responsáveis pela precipitação pluvial e o Anticiclone Subtropical do Atlântico Sul e o Vórtice Ciclônico de Ar Superior que, dependendo das suas posições, ocasionam grandes períodos de estiagens. (Minuzzi et al., 2007). 
Fragoso \& Gomes (2008) aplicaram a Análise Fatorial em Componentes Principais (ACP) a dados de chuva na região Sul de Portugal, para identificar padrões espaciais de precipitação associados a eventos intensos. Os resultados mostraram que na região do Algarve as chuvas de forte caráter torrencial foram mais frequentes. A maior predominância de dias com chuva ocorreu no outono e no início do inverno. Cinco tipos de sistemas de circulação foram identificados, indicando uma considerável diversidade entre as condições de circulação atmosférica de grande escala, favorecendo a ocorrência de chuvas torrenciais.

Stathis \& Myronidis (2009) aplicaram ACP a uma série de dados de 35 anos de precipitação em 75 estações meteorológicas na Thessália (Grécia Central). Duas componentes principais foram obtidas e descreveram $87,7 \%$ da variância total dos dados. A primeira componente principal relacionou-se com a frequência de ciclones, enquanto a segunda descreveu a ocorrência de anticiclones e tipos de tempo não-gradientes (não teve padrão bem definido ou associado a nenhum sistema de escala sinótica).

Silva \& Reboita (2011) ao estudar a passagem de frentes frias na região Sul de Minas Gerais de 2004 a 2010, encontraram 231 frentes frias com média anual de 33 frentes para a área estudada. Segundo os autores, a menor ocorrência de frentes no verão foi devido ao enfraquecimento dos gradientes de temperatura do Hemisfério Sul. Já no inverno, a atuação do Anticiclone Subtropical do Atlântico Sul, que nessa época do ano está mais intenso e deslocado para oeste, impediu a chegada das frentes.

Amanajás \& Braga (2012) aplicarm a ACP a dados mensais de precipitação na Amazônia Oriental, relacionando-os com os principais mecanismos climáticos dos oceanos Pacífico e Atlântico tropicais. Os resultados mostraram que o primeiro fator definiu áreas de chuva que são influenciadas pela atuação da Zona de Convergência Intertropical (ZCIT). No segundo fator, áreas de atuação dos eventos de meso escala tal como Linhas de Instabilidades (LI) foram evidenciadas, favorecendo as chuvas na região nos meses de maio a agosto. E o terceiro padrão espacial indicou a influência da atuação da ZCAS, sistema atuante no final da primavera e início do verão, bem como sistemas de escala local. Recentemente, Santos (2013) utilizou a Análise em Componentes Principais e Agrupamentos para determinar padrões espaciais do Índice de Precipitação Normalizado (SPI) e regiões homogêneas de eventos extremos de chuva no Estado do Pará.

Este estudo objetiva quantificar e analisar a variabilidade espacial e temporal da razão de mistura no Estado de Minas Gerais e associá-las a sistemas meteorológicos de grande e meso escalas que, por ventura, atuam naquela região.

\section{Material e Método}

\section{Área de estudo}

O Estado de Minas Gerais é uma das 27 unidades da República Federativa do Brasil, na América do Sul. Está localizado na região Sudeste do Brasil, juntamente com os Estados do Espírito Santo, Rio de Janeiro e São Paulo (Figura 1). Seu território fica entre os paralelos 14¹3'58'e

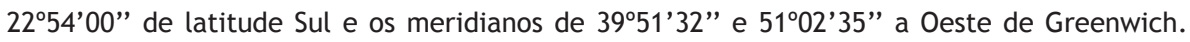
Ocupa um fuso horário correspondente a -3 horas em relação a Greenwich. 0 Estado faz divisa com São Paulo (Sul e Sudeste), Rio de Janeiro (Sudeste), Mato Grosso do Sul (Oeste), Goiás e Distrito Federal (Noroeste), Espírito Santo (Leste) e Bahia (Norte e Nordeste) (Minas Gerais, 2014). 


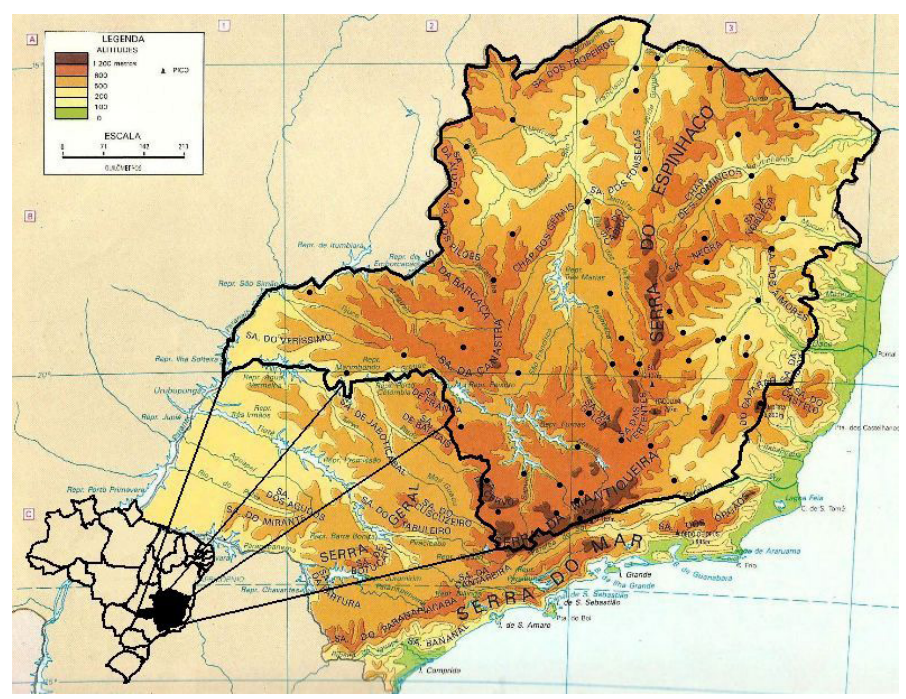

Figura 1. Espacialização das estações climatológicas no Estado de Minas Gerais/Brasil. Adaptado de Simielli (1991).

\section{Método}

Utilizaram-se séries mensais de Pressão, Temperatura, Umidade Relativa e Precipitação para um período comum de 30 anos (1961-1990) de 39 estações climatológicas selecionadas do Instituto Nacional de Meteorologia (INMET) para o Estado de Minas Gerais.

0 método da ACP consiste em transformar $p$ variáveis originais correlacionadas em componentes não correlacionadas ou ortogonais, tendo propriedades especiais em termos de variância. As novas componentes são funções lineares das variáveis originais e mostradas em ordem decrescente de importância, ou seja, a primeira componente é a combinação linear de importância máxima (Marques e Mendes Marques, 2005). Utilizou-se o modo de rotação ortogonal Varimax onde os componentes originais passaram a ser rotacionadas através da redistribuição dos pesos entre as CPs. Maiores descrições da metodologia podem ser encontradas em Wilks (2006) e Richman (1986).

\section{Discussão dos Resultados}

As Figuras $2 \mathrm{a}$ e $2 \mathrm{~b}$ mostram, respectivamente, à variabilidade média da razão de mistura e o mapa de Bacias Hidrográficas para o Estado de Minas Gerais. 


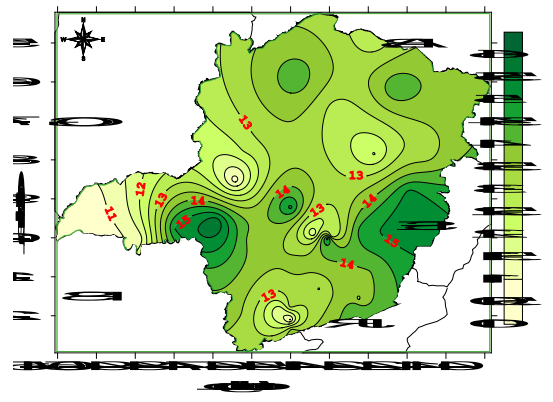

(a)

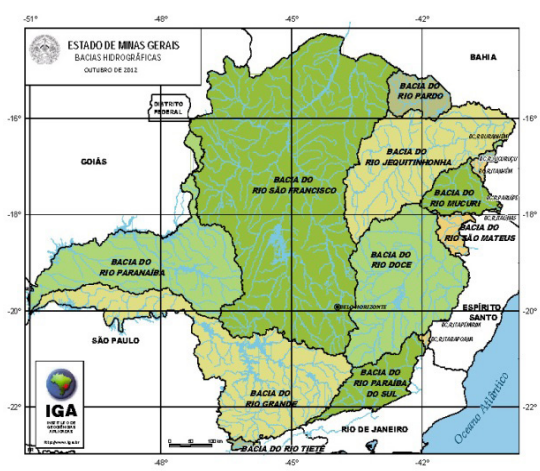

(b)

Figura 2. Carta média de razão de mistura $(\mathrm{g} / \mathrm{Kg})(\mathrm{a})$ e mapa das Bacias Hidrográficas (b) do Estado de Minas Gerais/Brasil (IBGE, 2014).

A variabilidade espacial média da razão de mistura não é muito acentuada. Três núcleos com maior concentração de vapor d'água podem ser destacados: um deles no sudoeste do Estado, na região do conjunto de represas das Bacias do Rio Grande e Rio Paranaíba, outro na região central, na Bacia do São Francisco, e o terceiro no leste mineiro, sobre a Bacia do Rio Doce, mostrando a importância dessas Bacias (influência local) na disponibilidade de água na atmosfera. Sistemas de curto prazo ocorrem geralmente no final da tarde e início da noite, quando células convectivas se desenvolvem em regiões de condições favoráveis (Novais, 2011). Os resultados mostram que o verão é a época do ano que possui maior disponibilidade de vapor d'água na atmosfera de Minas Gerais. A aplicação da ACP aos dados médios mensais da razão de mistura resultou na retenção de dois fatores que explicaram $97,86 \%$ da variância total dos dados. 0 primeiro fator tem correlações positivas superiores a 0,8 nos meses de dezembro a fevereiro e correlações da ordem de 0,75 , nos meses de março, outubro e novembro. 0 período melhor correlacionado a esse fator (outubro-março) pode está associado a ZCAS.

As contribuições negativas desse fator podem está relacionadas com a baixa umidade sobre a Serra do Espinhaço, prolongando-se até o extremo sul, sobre a Serra das Vertentes (Figura 3). Núcleos com contribuições negativas são observados nas Serras da Canastra e da Barcaça. Desse modo, esse fator também mostra a influência da irregularidade topográfica na distribuição da razão de mistura. 


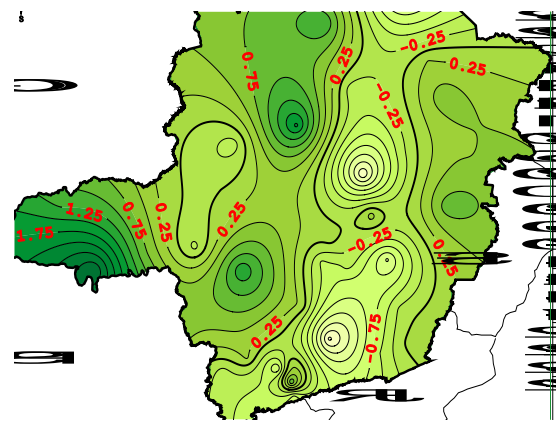

(a)

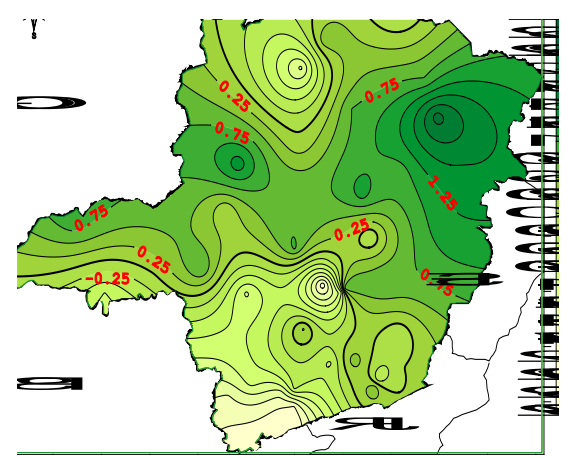

(b)

Figura 3. Padrão espacial associado ao primeiro (a) e segundo (b) fatores comuns dos totais médios mensais da razão de mistura no Estado de Minas Gerais.

Na porção leste, o primeiro fator associa-se à ocorrência de sistemas frontais, onde se percebe valores positivos (Figura 3a).

O segundo fator comum apresentou fortes correlações (superiores a 0,75 ) nos meses de maio a agosto. A espacialização deste fator indica contribuições elevadas nas porções leste e nordeste (Figura 3b). Observam-se também contribuições significativas, da ordem de 0,75 , no oeste de Minas nos meses de inverno. Este padrão mostra claramente o período mais seco, devido à queda de umidade provocada justamente pelo posicionamento do Anticiclone Subtropical do Atlântico Sul (ASAS), que nessa época do ano está mais intenso e deslocado para oeste, impedindo a chegada das frentes no sul de Minas Gerais. Excetua-se, neste caso, o cinturão leste/oeste influenciado pelos sistemas frontais, principais causadores de chuva no inverno.

\section{Conclusões}

A análise temporal e espacial desses fatores permitiu identificar sistemas atmosféricos que influenciaram na quantidade de vapor d'água (umidade) da região, possibilitando compreender melhor os mecanismos físicos geradores das chuvas.

O primeiro fator mostrou altas correlações da razão de mistura nos meses de outubro a março e está associado à atuação da ZCAS, sistemas frontais e aspectos orográficos. O segundo fator mostrou que as maiores contribuições ocorreram no inverno e está relacionado à baixa umidade provocada pelo deslocamento do Anticiclone Tropical na direção do continente.

$\mathrm{O}$ conhecimento de alguns aspectos das condições dinâmicas e físicas de Minas Gerais permite o desenvolvimento de políticas públicas com vistas à mitigação de consequências nocivas à sociedade, à agricultura e ao gerenciamento dos recursos hídricos daquela região.

\section{Bibliografia}

Amanajás, J. C.; Braga, C. C. (2012) - Padrões espaço-temporal pluviométricos na Amazônia Oriental utilizando análise multivariada. Revista Brasileira de Meteorologia, vol. 27, n. 4, p. 423-434.

Fragoso, M.; Gomes, P. T. (2008) - Classification of daily abundant rainfall patterns and associated large-scale atmospheric circulation types in Southern Portugal. International Journal of Climatology, 28:537-544. Instituto Brasileiro de Geografia e Estatística (2014) - Mapas de Biomas e de Vegetação. Disponível em: <http://www.ibge.gov.br>. Acesso em: 11 fev. 2014. 


\section{CAPÍTULO 3.2: RISCOS CLIMÁTICOS E HIDROLÓGICOS}

Marques, J. M.; Mendes Marques, M. A. (2005) - As componentes principais no descarte de variáveis em um modelo de regressão múltipla. Revista FAE, vol. 8, n. 1, p. 93-101.

Minas Gerais (Estado). (2014) - Portal do Governo de Minas Gerais. Disponível em: <http://www.mg.gov.br/ governomg/portal/c/governomg/conheca-minas>. Acesso em: $11 \mathrm{fev.} 2014$.

Minuzzi, R. B. et al. (2007) - Climatologia do comportamento do período chuvoso da Região Sudeste do Brasil. Revista Brasileira de Meteorologia, vol. 22, n. 3, p. 338-344.

Novais, G. T. Caracterização climática da mesorregião do Triângulo Mineiro/Alto Paranaíba e do entorno da Serra da Canastra. (2011) - Dissertação (Mestrado em Geografia) - Instituto de Geografia, Universidade Federal de Uberlândia, Uberlândia, 175 p.

Richman, M. B. (1986) - Rotation of principal components. International Journal of Climatology, 6:293-335.

Santos, S. R. Q. Determinação de regiões homogêneas do índice de precipitação normalizada (SPI) no Estado do Pará por meio da análise multivariada. (2013) - Dissertação (Mestrado em Meteorologia) - Programa de Pós-Graduação em Meteorologia, Universidade Federal de Campina Grande, Campina Grande, 97 p.

Silva, L. J.; Reboita, M. S. (2011) - Climatologia de Sistemas Frontais na cidade de Itajubá - MG. In: Jornada de Iniciação Científica, Tecnológica e de Inovação. (2011). Itajubá. Anais... Universidade Federal de Itajubá, 82 p.

Simielli, M. E. (1991) - Geoatlas. São Paulo, Editora Ática, 112 p.

Stathis, D.; Myronidis, D. (2009) - Principal component analysis of precipitation in Thessaly Region (Central Greece). Global NEST Journal, 11:467-476.

Vianello, R. L.; Alves, A. R. (1991) - Meteorologia básica e aplicações. Viçosa, Imprensa Universitária, UFV, $449 \mathrm{p}$.

Wilks, D. S. (2006) - Statistical Methods in the Atmospheric Sciences. London, Academic Press, 649 p. 